\title{
Genetic disease
}

\section{HLA system and rheumatic disease}

\author{
D. A. BREWERTON
}

From the Rheumatology Department, Westminster Hospital, London

Over 50 HLA antigens are now recognisable. Since we each have four antigens there are millions of possible combinations that characterise us as individuals. In humans these antigens are coded for in the major histocompatibility complex on the sixth chromosome. The loci for three of the complement components ( $\mathrm{C} 2, \mathrm{C} 4$, and factor $\mathrm{B})$ are in or near the major histocompatibility complex. In mice and other animals many genes controlling specific immune responses segregate in the same region as the genes for histocompatibility antigens. Equivalent human immune response genes have not yet been positively identified. Studies of inbred mouse strains have revealed a histocompatibility antigen $(\mathrm{H}-\mathrm{Y})$ controlled by the male $\mathrm{Y}$ chromosome, and there is good evidence that the $\mathrm{H}-\mathrm{Y}$ antigen is present in man.

In mice certain histocompatibility antigens are associated with susceptibility to particular diseases, the best examples being acute lymphocytic choriomeningitis, autoimmune thyroiditis, and leukaemia produced by viruses. The list of human diseases associated with HLA antigens grows day by day and includes disorders as diverse as multiple sclerosis, coeliac disease, psoriasis, juvenile diabetes, and haemochromatosis (Dausset and Svejgaard, 1977). The mechanisms by which HLA antigens may be associated with disease susceptibility have been the subject of extensive investigation and speculation. Some believe that the antigens play a direct part in disease processes, acting by mechanisms yet to be agreed. Alternatively, the importance of the HLA antigens may be in the close association of their heredity with other, more relevant, gene products. Since the genetic region between HLA-B and HLA-D is expected to contain immune response genes this may explain why most disease associations established so far have been with $\mathbf{B}$ or $\mathbf{D}$ antigens.

\section{Ankylosing spondylitis}

The most striking association has been between HLA-B27 and ankylosing spondylitis. An individual born with B27 is 300 times more likely than normal to develop classical ankylosing spondylitis (Bluestone, 1977). Studies of spondylitis in widely differing ethnic groups have provided conflicting evidence on whether B27 may be directly involved in the disease process. In most populations the degree of association between B27 and spondylitis has been remarkably similar, even when the incidence of B27 in the population is very high, as in the Haida Indians, or very low, as in the Japanese. This suggests that the B27 gene and a hypothetical disease susceptibility gene may be identical. But in a few populations - for example, black Americans or more particularly the Pima Indians - the association between B27 and spondylitis is much less, a finding more in keeping with the hypothesis of linked genes with varying degrees of linkage disequilibrium in different ethnic groups.

\section{Acute anterior uveitis}

About one-third of patients with ankylosing spondylitis also have attacks of acute anterior uveitis, but in many respects the uveitis does not behave as a complication. Since B27 is present in $40 \%$ of patients with uveitis without rheumatic disease the association between spondylitis and uveitis is now believed to be genetically determined (Brewerton, 1975).

\section{Seronegative peripheral arthritis}

Similarly, one-third of patients with ankylosing spondylitis have peripheral arthritis, particularly in the lower limbs. As with uveitis, B27 may predispose to seronegative peripheral arthritis without sacroiliitis or spondylitis. This form of peripheral arthritis tends to have the same joint distribution and clinical characteristics as the arthritis that accompanies ankylosing spondylitis (Milazzo, 1977).

\section{Chronic inflammatory bowel disease and psoriasis}

Ulcerative colitis and Crohn's disease have no genetic 
marker, while psoriasis is associated with HLA-Cw6 (Tiilikainen et al., 1977). When classical spondylitis is associated with chronic inflammatory bowel disease or psoriasis about $65 \%$ of the patients have B27. This supports the long-standing belief that the association between these disorders may be genetically determined. There is also the important question of why, when chronic inflammatory bowel disease or psoriasis are added to spondylitis, the incidence of B27 is less than the $90-95 \%$ found in ankylosing spondylitis on its own. The most likely explanation is that gene products predisposing to bowel or skin disease themselves contribute to the spondylitic process and make the presence of B27 less necessary.

\section{Reactive arthritis and Reiter's disease}

The term 'reactive arthritis' is more a concept than a diagnosis. It is used to describe an infection of a distant site such as the pharynx, gut, or genitourinary tract causing arthritis, presumably by an immunological reaction, without the infective agent invading the joint. Rheumatic fever and Reiter's disease are commonly quoted as examples. In clinical practice the diagnosis has mostly been applied to the arthritis following gut infection with Shigella or Salmonella species or with Yersinia enterocolitica. Individuals who have infection of the gut with these organisms are about 50 times more likely to develop acute arthritis two to six weeks later (Aho et al., 1974).

There is a similar relationship between B27 and Reiter's disease, whether it follows urethritis or dysentery. B27 is not associated with the initial response in the urogenital or intestinal tracts but with the subsequent reaction in the joints and other tissues.

\section{Sarcoidosis}

Early studies of HLA in sarcoidosis as a whole were disappointing. It has now been shown that patients with sarcoidosis who have HLA-B8 are appreciably more likely to develop arthritis (Brewerton et al., 1977). This association with $\mathrm{B} 8$ applies in patients with arthritis alone, with arthritis and erythema nodosum, and with erythema nodosum alone. Thus there seems to be an inherited susceptibility to arthritis and to erythema nodosum, both having B8 as a genetic marker. It is not yet known whether B8 is associated with erythema nodosum in other clinical situations.

\section{Sjögren's syndrome}

B8 is also associated with Sjögren's syndrome although not in the presence of rheumatoid arthritis. Recently, it has been established that Sjögren's syndrome is more closely associated with Dw3 (Iványi et al., 1976).

\section{Rheumatoid disease}

Individuals with HLA-Dw4 are about seven times more prone to develop classical, seropositive, rheumatoid arthritis (Stastny, 1976), and there is a slightly closer association with DRw4 (Stastny et al., 1977; Bodmer et al., 1977).

\section{Fibrosing alveolitis}

Fibrosing alveolitis (without rheumatic disease) is believed to be associated with HLA-B12 (Evans and Evans, 1975). In fibrosing alveolitis alone there is also an increased incidence of the $\alpha 1$ antitrypsin phenotype $M Z$, while in patients with rheumatoid arthritis and fibrosing alveolitis there is an increased incidence of both MZ and MS (Geddes et al., 1977). Thus two genetic systems seem to be involved in this clinical combination - the major histocompatibility complex (for fibrosing alveolitis and for rheumatoid arthritis) and the Pi system. The latter system is on a different chromosome, where it is in genetic linkage with the $\mathrm{Gm}$ system.

\section{Conclusion}

With remarkable rapidity an overall pattern is emerging. We have to explain an immensely complilicated, overlapping relationship between many diseases, individual clinical features, and syndromes. At the same time scientists are groping to understand an equally complicated genetic region whose gene products may interact to modify each other's actions. There is now an intriguing prospect that when the endeavours of clinicians and scientists can be matched more adequately we may be able to discern how individuals are born susceptible to a wide range of diseases.

\section{References}

Aho, K., Ahvonen, P., Lassus, A., Sievers, K., and Tiilikainen, A. (1974). HL-A27 in reactive arthritis: a study of Yersinia arthritis and Reiter's disease. Arthritis and Rheumatism, 17, 521-526.

Bluestone, R. (1977). In Immunogenetics and Rheumatic Disease, edited by D. A. Brewerton. Saunders, London.

Bodmer, J. G., Mann, J., Hill, A., Hill, H., Young, D., and Winearls, B. (1977). The association of Ia antigens with juvenile onset diabetes and rheumatoid arthritis. Tissue Antigens., 10, 197.

Brewerton, D. A. (1975). HL-A27 and acute anterior 
uveitis. Annals of the Rheumatic Diseases, 34, Suppl. 1, 33-35.

Brewerton, D. A., Cockburn, C., James, D. C. O., James, D. G., and Neville, E. (1977). HLA antigens in sarcoidosis. Clinical and Experimental Immunology, 27, 227-229.

Dausset, J., and Svejgaard, A. (1977). HLA and Disease. Munksgaard and Williams and Wilkins, Copenhagen and Baltimore.

Evans, C. C., and Evans, J. M. (1975). HL-A in Farmer's lung. Lancet, 2, 975.

Geddes, D. M., Webley, M., Brewerton, D. A., Turton, C. W., Turner-Warwick, M., Murphy, A. H., and Milford Ward, A. (1977). a1-antitrypsin phenotypes in fibrosing alveolitis and rheumatoid arthritis. Lancet, 2, 1049-1051.

Iványi, D., Hincová, E., Šla, K., Drízhal, I., Erbenova,
E., Macurová, H., Dostál, C., Horejš, J., and Balík, J. (1976). HLA and Disease: Abstracts, VII-10. INSERM, Paris.

Milazzo, S. C. (1977). In Immonogenetics and Rheumatic Disease, edited by D. A. Brewerton. Saunders, London. Stastny P. (1976). Mixed lymphocyte cultures in rheumatoid arthritis. Journal of Clinical Investigation, 57, 1148-1157.

Stastny, P., Sittler, S., and Fink, C. W. (1977). Ia-like antigens in rheumatoid arthritis (RA), systemic lupus erythematosus (SLE) and chronic active hepatitis (CAH). Tissue Antigens, 10, 210.

Tiilikainen, A., Lassus, A., Pirskanen, R., Vartiainen, P., and Awellán, G. (1977). An attempt to evaluate Ia type antigens in patients with psoriasis or myasthenia gravis. Tissue Antigens, 10, 203. 